\title{
La función del metal entre los grupos campaniformes. Oro versus cobre. El ejemplo de la Región de Madrid (1)
}

\author{
Metal functions between Bell Beakers groups. Gold versus copper. \\ The example in the Region of Madrid
}

\author{
Concepción Blasco $\left(^{*}\right)$ \\ Patricia Ríos $(*)$
}

\section{RESUMEN}

El trabajo ofrece una visión renovada de la metalurgia del Horizonte campaniforme en Madrid a partir de los datos que aportan las recientes intervenciones en el yacimiento de Camino de las Yeseras. Sus contextos funerarios no se ajustan a los convencionalismos conocidos para estas tumbas pues las armas ausentes en los ajuares singulares son sustituidas por ornatos de oro y otras piezas realizadas en materias exóticas.

\begin{abstract}
This paper offers an overview of the Bell Beaker metallurgy in Madrid. This is a renewed vision thanks to data provided by the recent excavations in Camino de las Yeseras, a big settlement whose funerary contexts do not match the known conventions in these graves, for example, weapons - absent in the grave goods-are replaced with gold ornaments and other items made in exotic raw materials.
\end{abstract}

(*) Departamento de Prehistoria y Arqueología, Universidad Autónoma de Madrid. Correos electrónicos:

concepcion.blasco@uam.es y patricia.rios@uam.es.

Recibido: 19-II-2010; aceptado: 12-IV-2010.

(1) Investigación financiada por los siguientes proyectos: Economía y sociedad durante el Calcolítico de la Meseta: el yacimiento de Camino de las Yeseras (San Fernando de Henares, Madrid). Recursos minerales y actividades $I+D H U M$ 2007-6405 dirigido por Javier Baena; Materiales y recursos arqueobiológicos durante el III Milenio a.C. en la Comunidad de Madrid CCG08-UAM/HUM 4061 dirigido por Corina Liesau; Poblamiento de Madrid en el III Milenio a.C. Comunidad de Madrid Dir. Gral. de Patrimonio Histórico: 1635/2007/00 dirigido por Concepción Blasco; Programa I+D entre Grupos de Investigación de la Comunidad de Madrid: Patrimonio Arqueológico y Documental de la Comunidad de Madrid (PADCAM): S2007/HUM-0543 coordinado por Concepción Blasco.
Palabras clave: Arqueología de la Muerte; Península Ibérica; Calcolítico; Metalurgia; Valor social; Campaniforme; Recintos de fosos; Madrid.

Key words: Archaeology of the Dead; Iberian Peninsula; Chalcolithic; Metallurgy; Social value; Bell Beaker; Ditched enclosures; Madrid.

\section{INTRODUCCIÓN}

Desde hace ya varias décadas está plenamente constatado que en tierras del interior de la Península Ibérica, y más específicamente en territorio madrileño (Fig. 1), la metalurgia se practica y generaliza en torno a la segunda mitad del III milenio a.C., en el Horizonte campaniforme y, en particular, asociada a los grupos con campaniforme

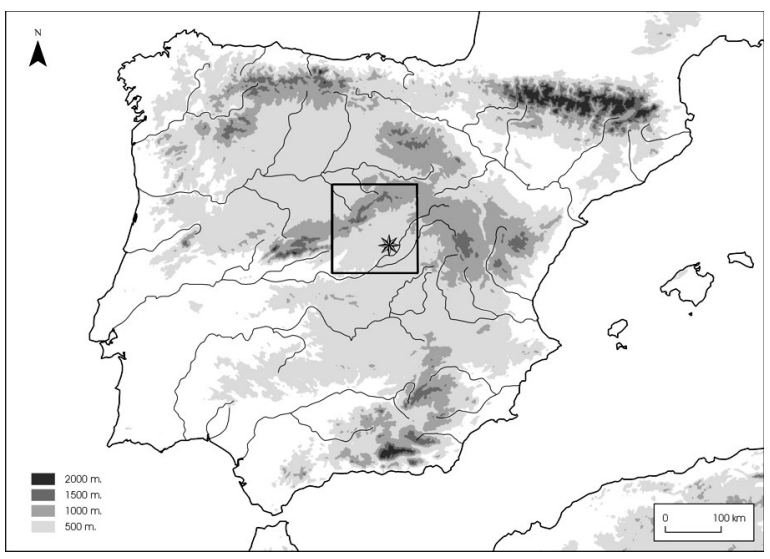

Fig. 1. Localización general del área de estudio y del yacimiento de Camino de las Yeseras (San Fernando de Henares, Madrid). 
Ciempozuelos aunque ello no impide que desde el inicio de este milenio llegaran o se elaboraran, de manera regular o esporádica, algunos objetos metálicos de escasa entidad.

En efecto, de momento, las primeras evidencias de dicha actividad se han documentado en asentamientos, muchos de ellos de apenas unos centenares de metros cuadrados, y posiblemente de ocupación limitada, en los que está presente la cerámica campaniforme. Asimismo son los enterramientos con campaniforme los primeros que normalizan la inclusión de objetos metálicos en los ajuares funerarios de algunas de las tumbas de especial significado. Pese a todo, la circulación de metales es todavía escasa ya que aproximadamente sólo el $20 \%$ de los yacimientos madrileños de este horizonte han entregado ajuares metálicos, fundamentalmente de cobre y en mucha menor proporción de oro. Esta escasez de metal y de objetos metálicos explica la lógica consideración del prestigio que supone su uso y posesión y por tanto que sólo unos pocos lo incorporaron a sus ajuares domésticos y funerarios, una restricción que se llevaría a cabo mediante el control de su captación y procesos de transformación.

\section{LA METALURGIA DEL COBRE}

Aunque no son muchos los ejemplos documentados en la Región de Madrid, tenemos datos suficientes para saber, a través de las pruebas que viene aportando la arqueometría, que una parte de la demanda se cubría mediante el autoabastecimiento del mineral obtenido en las afloraciones existentes en las vetas de la propia sierra madrileña (Rovira y Montero 1994; Blasco y Rovira 1992-93; Montero 1998), a unas decenas de kilómetros de las cuencas medias y bajas de los ríos donde se concentraban la mayor parte de los asentamientos y también de los enterramientos. Posiblemente la actividad destinada a la captación de los minerales del cobre se asociaba a la obtención de otras materias primas necesarias para la fabricación de enseres pesados como hachas, azuelas, mazas, etc., o a elementos de trituración y molienda, incluso al aprovisionamiento de piedras duras empleadas en ornatos personales (Baena y Blasco 1999).

Pero creemos que los productos metálicos de esta etapa derivados de la actividad extractiva lo- cal pudieron y de hecho debieron de ser compatibles con la obtención de materia prima en yacimientos más o menos lejanos y con la adquisición de algunas piezas procedentes de otros talleres que llegarían a esta zona ya acabadas, bien por intercambio, bien como donaciones o regalos para incorporarse directamente a los enseres domésticos de uso habitual y a los ajuares funerarios. Al menos así podría derivarse de los resultados de algunas analíticas practicadas que indican la presencia de elementos minoritarios como el níquel muy escaso o ausente en las mineralizaciones conocidas del Sistema Central más próximas a los yacimientos. Ahora bien en la mayoría de las ocasiones la obtención de estos objetos de procedencia foránea no tuvo por qué revestir carácter de excepcionalidad, sino que estaría dentro de la circulación de materias primas y objetos intercambiados en trueques habituales.

Fue precisamente la Región de Madrid una de las primeras áreas del interior peninsular que aportó pruebas evidentes sobre cómo la transformación de los minerales del cobre se realizaba en asentamientos de pequeñas dimensiones con una tecnología muy sencilla ya que no requería ningún tipo de infraestructura estable, pues utiliza hornos móviles consistentes en vasijas, muchas veces amortizadas y rotas (Rovira y Ambert 2002), y crisoles barquiformes o circulares muy homogéneos (Simon 1996), hechos en barro sin cocer y de tamaño bastante reducido. Se trata de la misma tecnología que se ha documentado en yacimientos sincrónicos de otras áreas de la Península Ibérica. Esta uniformidad de los objetos de fundidor habla de una clara estandarización de la actividad.

Entre los yacimientos con indicios de esta industria hay que mencionar el Ventorro, conocido desde hace tiempo (Harrison et al., 1975) por haber entregado algunos fragmentos de crisoles con decoraciones campaniformes de estilo Ciempozuelos (Fig. 2a) a los que hay que unir los restos de recipientes hornos realizados con las mismas características y morfologías de las vajillas comunes (Fig. 2b) (Priego y Quero 1992). Muy cercano a este yacimiento, en el arenero Soto, se recuperó también un gran fragmento de recipiente horno y liso con abundantes gotas de fundición (Rovira 1989), en este caso asociado a campaniforme puntillado geométrico (Fig. 2c). La tecnología practicada en estos pequeños sitios no presenta diferencias con la estrategia de producción 

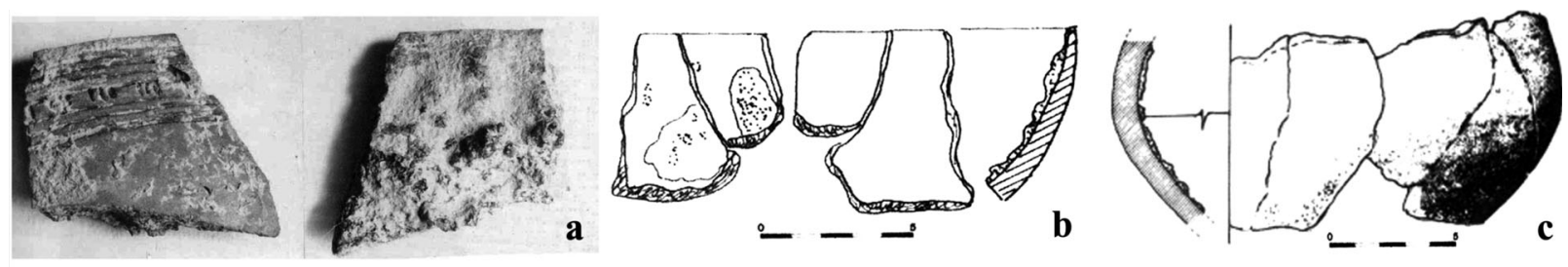

Fig. 2.a y b) Crisol campaniforme procedente de El Ventorro (Madrid) (Priego y Quero 1992: 305, Fig. 172 y 309, Lám. XXX). c) Fragmento de vasija horno procedente del Arenero de Soto (Perales del Río, Madrid) (Blasco y Rovira 1992-93: 413, Fig. 2).

documentada en grandes centros más o menos sincrónicos de ésta y de otras regiones peninsulares.

La similitud entre el procesado del metal practicado en pequeños y grandes asentamientos ha quedado plenamente contrastada en la Región de Madrid a partir de los recientes trabajos realizados en Camino de las Yeseras, un gran recinto de fosos con una extensión de algo más de 20 ha (Blasco et al. 2007; Liesau et al. 2008: 103-105). Allí a pesar de que las condiciones de la excavación no han sido favorables para la obtención de datos muy precisos, se han documentado evidencias relacionadas con los trabajos del cobre a través de los restos de mineral, de gotas de fundición (Fig. 3) y de objetos de fundidor (Fig. 4).

Algunos de los restos de fundición se localizaron dentro de una enorme subestructura que llega a alcanzar casi $2 \mathrm{~m}$ de profundidad, colmatada con un sedimento oscuro en el que se pueden apreciar 13 niveles, posiblemente depositados en un espacio de tiempo relativamente prolongado y como consecuencia de una reiterada utilización de la zona. El área excavada de esta subestructura es de unos $600 \mathrm{~m}^{2}$, pero su superficie total debió de ser, con seguridad, bastante mayor al prolongarse por el lado norte en una extensión que no ha

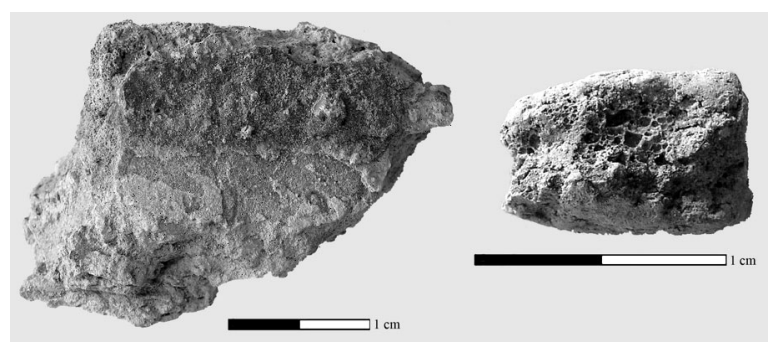

Fig. 3. Restos del mineral y gotas de fundición de cobre procedentes de Camino de las Yeseras (San Fernando de Henares, Madrid). podido ser delimitada. Esta gran subestructura se ubica en la zona central del yacimiento, en el espacio localizado en el recinto interior $y$, por tanto protegido por los cinco fosos concéntricos; en dicha subestructura se concentra una gran cantidad de materiales y restos orgánicos fruto de la intensa actividad desarrollada en su superficie, pero desgraciadamente los depósitos originarios se encuentran claramente alterados lo que hace difícil contextualizar los materiales (Fig. 5). Sin embargo la alta concentración de diversos restos industriales y faunísticos parece indicar que se trata de un área de actividad comunal en la que se realizaron, entre otros, trabajos industriales como la metalurgia o la talla lítica, ya que en una zona no muy alejada a los hallazgos de estas escorias se instaló un pequeño taller relacionado con la industria lítica que afortunadamente se conservaba en posición originaria.

De confirmarse que estos indicios son fruto del desarrollo de la actividad metalúrgica en dicho espacio, existe una coincidencia entre la función de esta área central y lo que se ha podido documentar en otros yacimientos calcolíticos de recintos amurallados como Los Millares donde el taller se encontraba también en una zona muy controlada, en el interior del segundo recinto (Molina y Cámara 2005: 45-47), o Cabezo Juré donde la reducción del cobre se efectuó en un único ámbito: la ladera sur, lo que permitió restringir su acceso y mantener el control (Nocete 2004: 122-125; Rodríguez 2008: 44). Asimismo, existen indicios, en algunos de los recintos de fosos localizados en el valle del Guadiana, como es el caso de La Pijotilla (Hurtado y Hunt 1999) y Perdigões (Varela 2004), que podrían indicar que las actividades metalúrgicas practicadas en ellos se localizan en zonas muy concretas y siempre dentro de los recintos concéntricos para facilitar su control. 

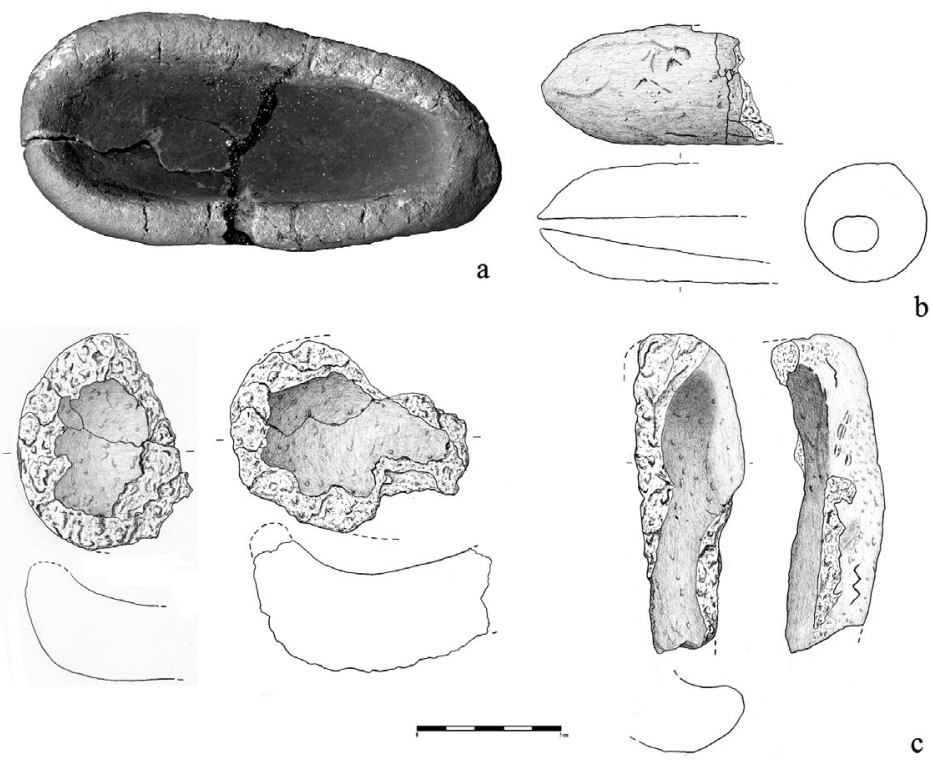

$\mathrm{b}$

Fig. 4. Objetos de fundidor procedentes de Camino de las Yeseras (San Fernando de Henares, Madrid).

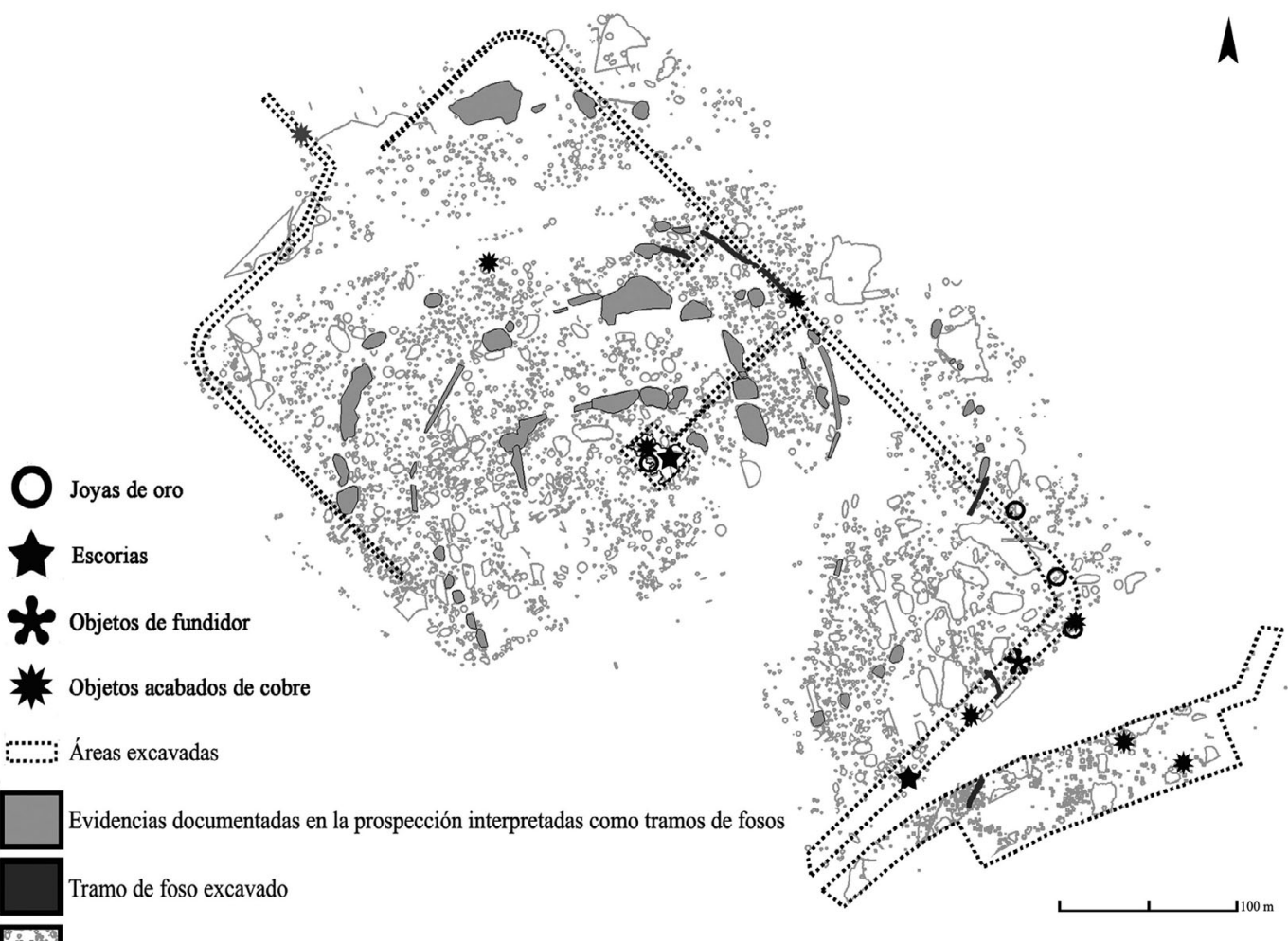

Planimetría a partir de la prospección de superficie

Fig. 5. Distribución de los objetos metálicos sobre la Planimetría general de Camino de las Yeseras (San Fernando de Henares, Madrid).

T. P., 67, N. ${ }^{\circ} 2$, julio-diciembre 2010, pp. 359-372, ISSN: 0082-5638 doi: $10.3989 /$ tp.2010.10044 
Pero en Camino de las Yeseras se recuperaron también algunos objetos de fundidor en un área periférica, dentro de un hoyo siliforme, datado en $3835 \pm 40$ BP (2), cuya presencia no sabemos si se debe a otra zona de actividad metalúrgica o a un traslado intencionado o fortuito (Fig. 4). Entre estos objetos cabe destacar una pequeña tobera, elemento escasamente documentado en el registro de este horizonte (Fig. 4b). La localización de este depósito en una zona periférica del yacimiento podría significar la práctica de una actividad descentralizada con producciones a distintas escalas, aunque tampoco pueda descartarse que estemos ante evidencias diacrónicas ya que a lo largo de la dilatada vida del yacimiento pudieron producirse cambios en el uso de las distintas zonas o incluso que el hoyo o cubeta donde se concentraban los útiles de fundidor no estuviera en una zona de trabajo sino en un entorno doméstico donde se habrían almacenado para su posterior utilización o para amortizarlas por tratarse de piezas inservibles.

Esta incipiente industria metalúrgica del calcolítico campaniforme madrileño realizada con minerales locales debió de estar dedicada a la elaboración de pequeños y sencillos útiles cotidianos entre los que destacan los punzones y leznas, los objetos más habituales en los contextos domésticos, pero en ningún caso se ha podido documentar exactamente los objetos fabricados en cada uno de los talleres debido a la ausencia de moldes en el registro arqueológico. Ello nos impide conocer si podemos estar ante una industria con dos niveles de producción, uno a escala doméstica para la elaboración de objetos menudos y muy sencilos de uso habitual y otro a nivel de especialistas donde se elaborarían las piezas de mayor tamaño y más complejas, destinadas a ajuares funerarios y consideradas de prestigio como los puñales, o incluso las puntas.

No hay, hasta el momento, ningún asentamiento que haya entregado una cantidad llamativa de metal, pues incluso el Ventorro, donde se recuperaron un total de 63 fragmentos de crisoles tan sólo proporcionó 3 fragmentos de punzones o barritas (Fig. 6a), una cantidad claramente inferior a la obtenida en Camino de las Yeseras, allí donde se han recuperado hasta 9 útiles cuyo peso total es de apenas $150 \mathrm{~g}$ (Fig. 6b), una cantidad relativamente exigua si tenemos en cuenta que

(2) 2460-2190 cal a.C. a $2 \sigma$, ref. Ua-35018.

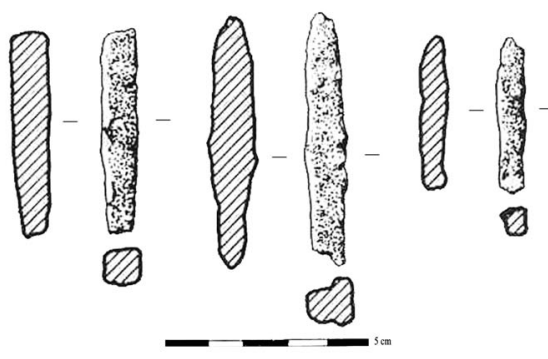

a

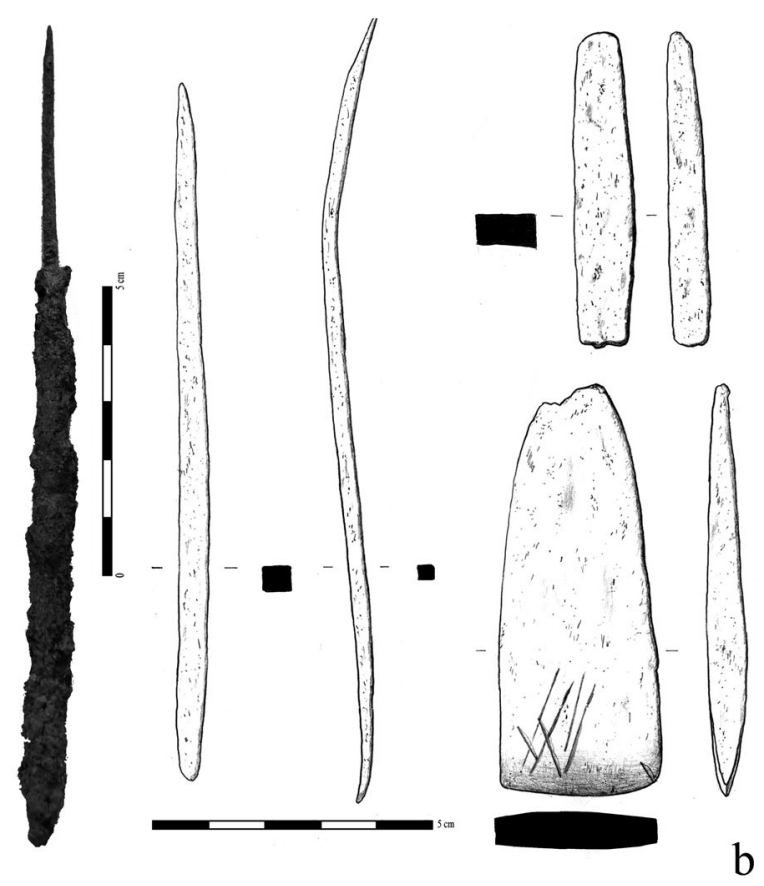

Fig. 6. Útiles de cobre de contexto doméstico: a) procedentes de El Ventorro (Madrid) (Priego y Quero 1992: 306, Fig. 174) y b) algunos de los hallados en Camino de las Yeseras.

los hallazgos se enmarcan dentro de una intervención de cierta envergadura que ha gernerado un volumen de materiales muy importante. Además, la cantidad de los objetos metálicos recuperados en este yacimiento dentro de contextos no funerarios (7) resulta superior a la que han entregado las tumbas (2), invirtiéndose así las proporciones habituales en otros yacimientos.

En efecto, en la Región de Madrid, como en otras áreas peninsulares, el registro arqueológico ha confirmado que una parte importante de la producción de la metalistería del cobre circulante en el Horizonte campaniforme, correspondía a las armas de la reducida panoplia que se amortizaba en determinados enterramientos pertenecientes a 
personajes de cierta relevancia. Ejemplo de ello son los puñales de lengüeta asociados a campaniforme de estilo internacional recuperados en el dolmen de Entretérminos (Fig. 7a) y en la sepultura en fosa del arenero de Miguel Ruiz (Madrid) (Fig. 7d), o los ajuares con puntas Palmela y puñal de lengüeta que acompañaban a ejemplares campaniforme de estilo Ciempozuelos de dos sepulturas en fosa de Mejorada del Campo (Fig. 7b) y una del Arenero de Salmedina (Rivas-Vaciamadrid) (Berzosa y Flores 2005: 490, Fig. 6). A ellos hay que sumar el puñalito de uno de los ajuares de la necrópolis epónima de Ciempozuelos, cuya morfología nos remite a una tipología más común en algunas necrópolis danubianas (Fig. 7c), una similitud que, al menos, podría indicar cierta interacción, o tratarse de una copia local.

Sin embargo, los dos únicos objetos de Camino de las Yeseras procedentes de enterramientos con ajuares de cerámica campaniforme Ciempozuelos son simples punzones (Fig. 7e), similares a los que se encuentran entre los enseres domésticos y, junto con las hachas planas, los únicos objetos de cobre presentes ya en la etapa precampaniforme. Es más, una de las tumbas que contenía uno de estos punzones y que estaba intacta no pertenece al estandar de un enterramiento singular, pues en su ajuar, a la cerámica campaniforme se une tan sólo el punzón y una piedra de molino. Es como si esta pieza tuviera, como el molino, un valor y un uso funcional, sin descartar su significado como prototipo de una nueva tecnología que aporta nuevas capacidades que, de momento, sólo están al alcance de un sector de la población identificado con los poseedores de la cerámica campaniforme (Blasco et al. 2005: 472, Fig. 11).

En contraposición la incorporación de armas -puntas y puñales- en los ajuares campaniformes
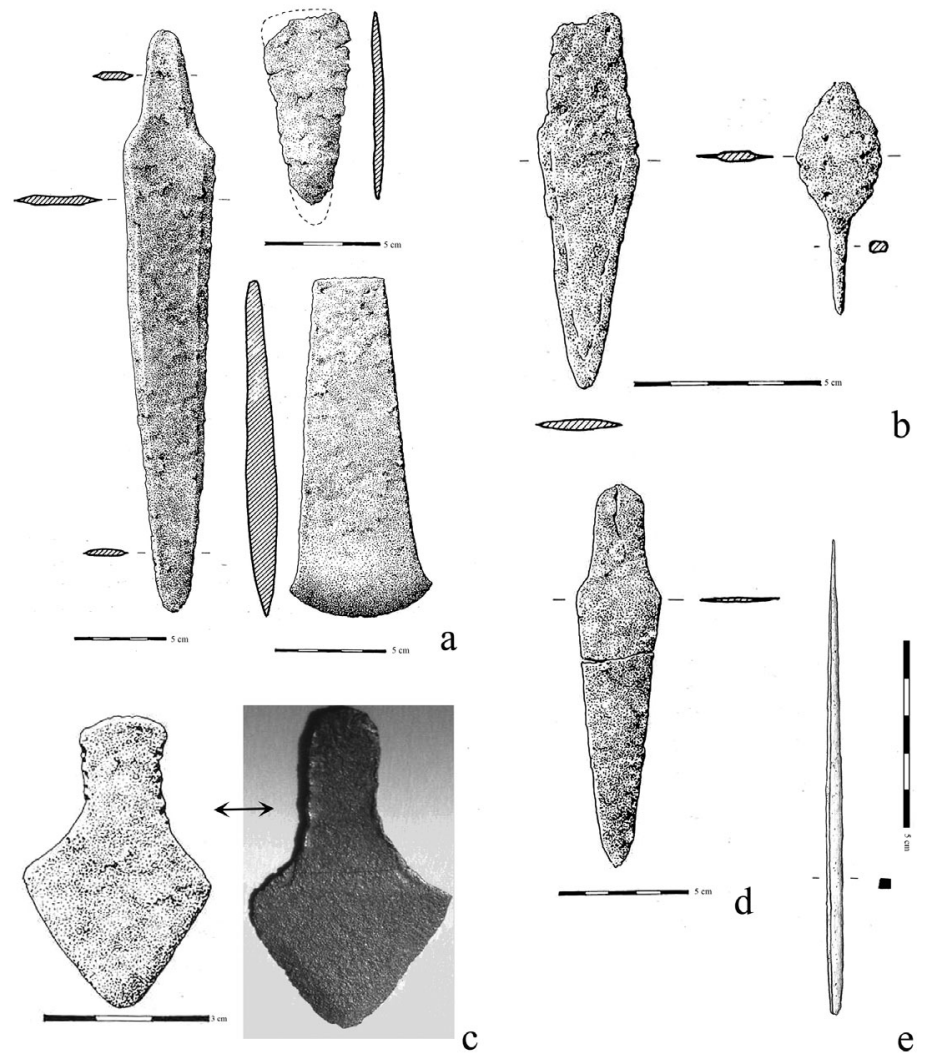

Fig. 7. Objetos de cobre de contexto funerario: a) ajuar del dolmen de Entretérminos (Losada 1976), b) puñal y punta palmela de Mejorada del Campo (Harrison 1977), c) a la izquierda puñal de Ciempozuelos (Blasco et al., 1998: 106, Fig. 20) y a la derecha puñal húngaro procedente de la necrópolis campaniforme de Békásmegyer (Budapest History Museum) y d) uno de los punzones de Camino de las Yeseras. 
se ha venido interpretando como el reflejo de una sociedad convulsa en una etapa de tránsito entre las sociedades igualitarias y las primeras jefaturas todavía no totalmente asentadas. ¿Por qué faltan en este caso?, la respuesta no es la ausencia de enterramientos destacados pues, como veremos, al menos tres de las tumbas exhumadas pertenecen a personajes singulares, pero exhiben su condición mediante objetos de lujo de atuendo personal, entre los que se encuentra sólo otro metal: el oro, cuya nobleza y/o significado lo convierte, como veremos, en objeto de deseo.

La singularidad tipológica del puñalito de Ciempozuelos, conocido desde finales del siglo XIX, pero sobre el que apenas se ha llamado la atención que reside en sus características tipométricas y lo vinculan de manera muy directa con ejemplares húngaros. De poder certificarse esta posible procedencia del área danubiana, significaría que para los grupos campaniformes de la región la posesión de determinadas armas adquiere una importancia tan primordial que justifica la ampliación del marco de su interacción a territorios muy lejanos, del interior continental, en consonancia con la obtención de otras materias y objetos de prestigio como es el marfil cuya proce- dencia extracontinental está hoy plenamente contrastada (Schuhmacher et al. 2007).

\section{LA ORFEBRERÍA ÁUREA (Fig. 8)}

La escasez de oro en los contextos calcolíticos peninsulares abarca al conjunto de las tierras del interior. La mayor parte de los hallazgos se concentran en la fachada occidental y, dentro de ella, en el oeste. Esto explica que hasta ahora la única pieza conocida en la Región de Madrid fuera una diadema consistente en una cinta lisa con los extremos perforados, desgraciadamente hoy desaparecida, recuperada en el ya mencionado dolmen de Entretérminos, posiblemente perteneciente al mismo ajuar en el que se encontraba el puñal de lengüeta y los vasos campaniformes marítimos. La reciente intervención en Camino de las Yeseras ha ampliado sensiblemente el número de contextos calcolíticos campaniformes con elementos de oro, los cuales compensan la ausencia en sus ajuares funerarios de objetos de cobre, y más concretamente de armas, considerados elementos de prestigio. De manera que los ornatos de oro, identificados como símbolos de osten-

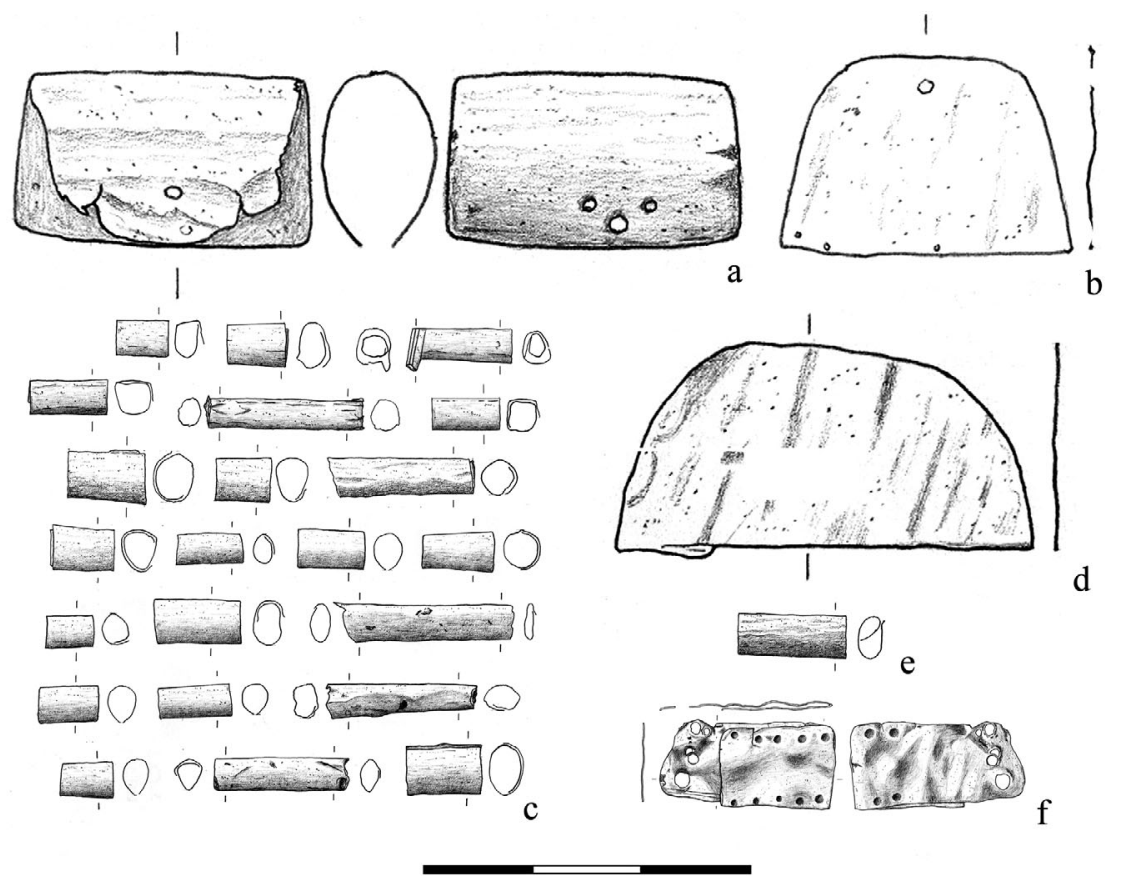

Fig. 8. Ornatos de oro documentados en Camino de las Yeseras (dibujos J.F. Blanco García, Universidad Autónoma de Madrid).

T. P., 67, N. ${ }^{\circ}$, julio-diciembre 2010, pp. 359-372, ISSN: 0082-5638 doi: $10.3989 /$ tp. 2010.10044 
tación, sustituyen en este yacimiento a las armas, símbolos de coerción. Así, a diferencia de otros ajuares campaniformes que evocan el prestigio de los difuntos exclusivamente por la presencia de armas o, en contadas ocasiones, por la suma de armas y ornatos realizados con materias preciosas y/o exóticas, entre ellos el oro, en $\mathrm{Ca}-$ mino de las Yeseras la distinción social se manifiesta exclusivamente por la donación de ornatos personales hechos con materias primas exóticas y de procedencia lejana.

Todas las piezas recuperadas, cuentas, cinta y placas, están realizadas a base de láminas de oro batido y recortado de forma muy irregular. Las cuentas tubulares se han obtenido a partir de pequeñas tiras rectangulares enrolladas, de desigual anchura, a veces con una doble vuelta y en ocasiones con una única espira, para obtener una morfología cilíndrica de perfil recto que no es privativa de las joyas áureas, sino que se utiliza desde el Neolítico en las confeccionadas con otro tipo de materiales como piedras, hueso, marfil, etc. Su elaboración poco uniforme y un tanto desmañada es habitual de la orfebrería peninsular del momento (Perea 1989: 27, 1991: 35-36), justificada por la todavía escasa trayectoria de esta actividad y por los pocos medios instrumentales disponibles para efectuar cortes y acabados finos. Este hecho se evidencia en el desigual tamaño de estas cuentas cuya longitud, pese a formar parte del mismo tocado, oscila entre los 4 y los $13 \mathrm{~mm}$ $\mathrm{y}$, sobre todo, en la escasa precisión que se observa en los irregulares cortes de las laminitas con rebabas y sobrepasados muy notorios (Fig. 8c).

La analítica ha proporcionado una extraordinaria homogeneidad entre todos los elementos recuperados, con tasas de plata de entre el 3 y el 5\% a excepción de una placa que es de oro prácticamente puro y que está realizada sobre una lámina sensiblemente más gruesa que el resto de las piezas (Fig. 8d). Dicha homogeneidad ha sido contrastada satisfactoriamente tras el análisis de tres cuentas tubulares por el método PIXE en el acelerador AGLAE del Museo del Louvre, por la Dra. María Filomena Guerra, a quien agradecemos su colaboración. En dichos análisis se detectaron también cantidades de cobre del orden de 0,02 a $0,05 \%$. De estos datos se desprende algo habitual en la orfebrería calcolítica de la Península Ibérica: la procedencia aluvial del oro en el que se confeccionaron estas joyas, caracterizado por una escasa presencia de cobre, no superior al $0,11 \%$
(Perea 1991: 31-35), una evidencia que confimaron los análisis realizados por Hartmann (1982) quien los englobó dentro del que denominó grupo S.

No se puede avanzar mucho más en la indagación de la procedencia geográfica del oro pues "por desgracia la información disponible sobre la composición del oro nativo peninsular es muy pobre - por no decir nula-. Están por hacer los estudios analíticos de las distintas cuencas auríferas" (Montero y Rovira 1991: 9). Pero no es menos cierto que, en la provincia de Guadalajara lindando con la de Madrid, han estado operando lavaderos auríferos hasta mediados del siglo XX en La Nava de Jadraque y Arroyo de la Fragua y también, más cerca, en Palancares, en la región del alto Jarama. Pese a ello no descartamos que estas joyas, lo mismo que la diadema procedente del dolmen de Entretérminos o la lámina en espiral del Vertedero de Salmedina (Berzosa y Flores 2005: 483), llegaran a su destino ya confeccionadas, procedentes de posibles talleres especializados desde donde se pudieron distribuir a todo el territorio peninsular.

La orfebrería áurea calcolítica se dispersaba, casi exclusivamente, por la fachada atlántica con una extensión hacia el sur (Hernando 1983: 117, Fig. 11), coincidiendo con los principales yacimientos auríferos (Sánchez Palencia y Pérez 1989, 17, Fig. 1). Sin embargo a medida que se han intensificado las investigaciones, sabemos que menudea por toda la geografía peninsular (Rodríguez de la Esperanza 2005). Los nuevos hallazgos madrileños se enmarcan en este mismo proceso de avance de la investigación y, sobre todo de intensificación de los trabajos de campo. Esta difusión podría indicar que las explotaciones auríferas abarcaron puntos diversos de la geografía peninsular o bien, como hemos apuntado, los propios talleres instalados en las proximidades de las zonas más ricas en oro pondrían sus productos en circulación a través de mecanismos de interacción facilitados por una red establecida para satisfacer la demanda.

La absoluta homogeneidad tipológica y técnica entre los objetos de oro calcolíticos de toda la Península Ibérica indica que se trata de modelos estandarizados indicio de una producción concentrada en unas pocas manos o de una gran interrelación entre los orfebres. Concretamente tanto la diadema acintada procedente del dolmen de Entretérminos, como la lamina en espiral de Sal- 
medina y las cuentas tubulares de perfil recto realizadas con pequeñas plaquitas rectangulares enrolladas de la diadema recuperada en Camino de las Yeseras, se encuentran con pequeñas variantes entre los hallazgos más comunes en este horizonte (Perea 1991: 26-27).

En la Península Ibérica esta producción de ornatos áureos estuvo destinada, casi en exclusividad, a la confección de ajuares funerarios como demuestran la práctica totalidad de los contextos en los que se encuentran: enterramientos megalíticos colectivos (Perea 1991: 24, Fig. 1 y 53), o tumbas con campanifomes, tanto impresos, como Ciempozuelos. Esta finalidad queda bien contrastada en Madrid por el hallazgo en el dolmen de Entretérminos, en la fosa 2 de Salmedina y en el registro de Camino de las Yeseras donde se localizaron en cuatro puntos distintos: tres en la periferia formando parte de ajuares funerarios y uno en la zona central del yacimiento, un espacio de intensa remoción por la prolongación de su uso (Fig. 5).

La finalidad funeraria de la orfebrería parece corroborarse por el escaso o nulo uso que han te- nido las joyas en general y las de Camino de las Yeseras en particular si tenemos en cuenta el dato aportado por la Dra. Guerra al inspeccionar las tres cuentas de uno de los hallazgos de Camino de las Yeseras en el microscopio electrónico de barrido: sus bordes no parecen presentar desgaste de uso, por lo que, si no fueron fabricados expresamente para formar parte del ajuar del difunto, apenas tuvieron un uso previo al de su destino final. Ello equipararía las joyas, armas y otros objetos de cobre como donaciones realizadas expresamente para los ajuares funerarios campaniformes a pesar de que el cobre es utilizado para la elaboración de úties de uso doméstico y laboral más o menos cotidianos.

Desgraciadamente sólo la diadema áurea corresponde a un contexto originario no alterado. Se trata de un hipogeo en el que se inhumó un individuo masculino, joven que la ostentaba y de la que se recuperaron 22 cuentas en torno al cráneo y dos placas subtrapezoidales sobre la frente (Fig. 8a, b y c, Fig. 9, Fig. 10). En una segunda tumba expoliada se recuperó otra cuenta semejante que debió de formar parte de una joya simi-
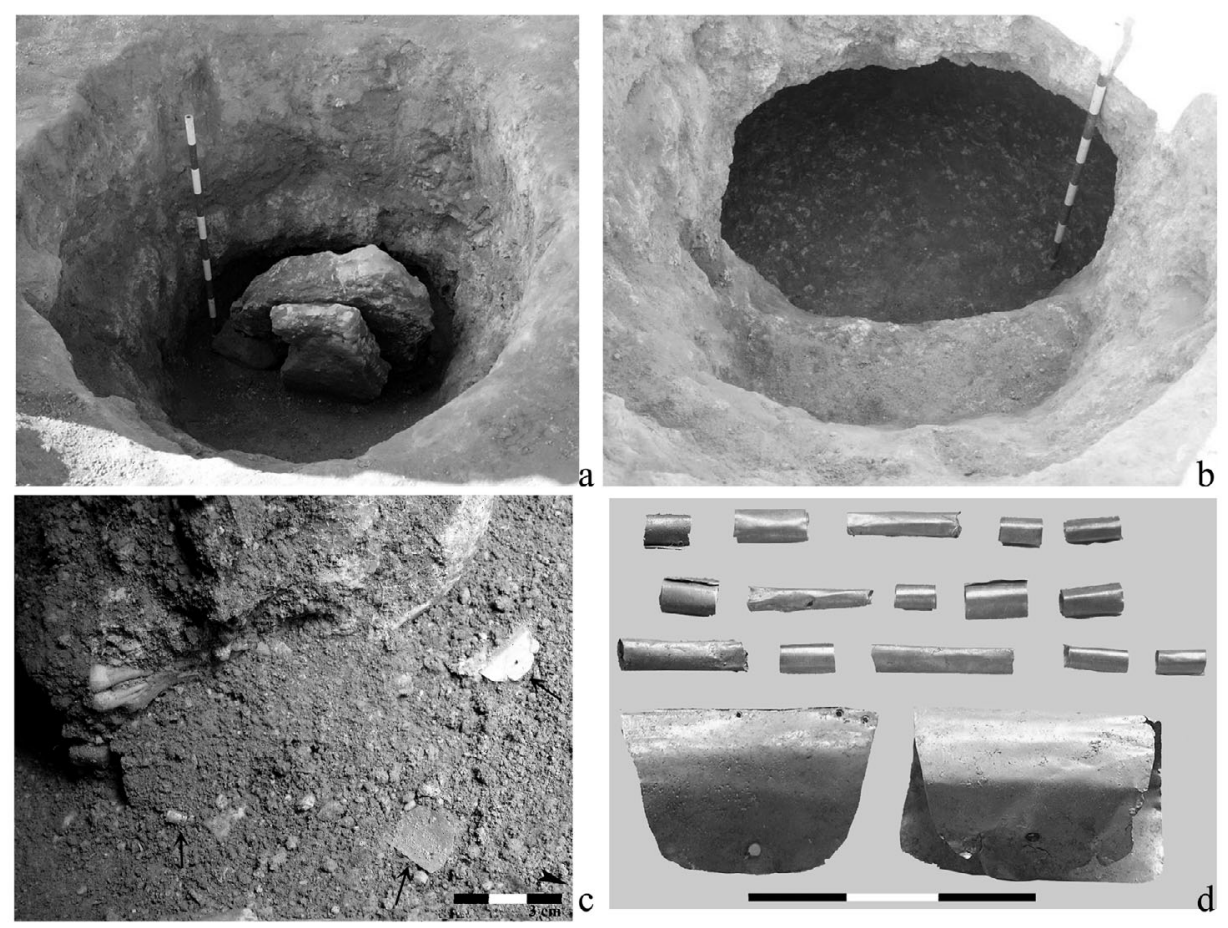

Fig. 9. Hipogeo de Camino de las Yeseras: a) vista del acceso y losas de cierre de la cámara, b) vista de la entrada, c) detalle de la disposición de cuentas y placas de oro en torno al cráneo del inhumado y d) placas subtrapezoidales y algunos ejemplos de cuentas tubulares. 


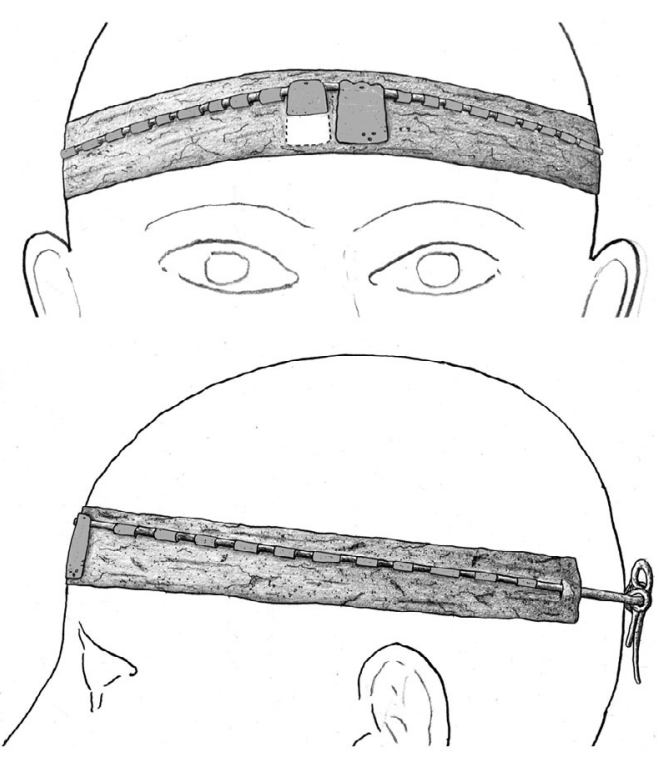

Fig. 10. Reconstrucción hipotética de la diadema de oro del joven inhumado en el hipogeo de Camino de las Yeseras (San Fernando de Henares, Madrid).

lar (Fig. 8e). La novedad es que estas cuentas enrolladas se habían interpretado como elementos de brazaletes o collares (Perea 1991: 26) o incluso como perlas o abalorios para aplicar sobre tejidos (Rodríguez de la Esperanza 2004). Ahora tenemos la seguridad de que entre los distintos tipos de ornatos también existieron diademas compuestas por diferentes elementos cuya composición permitiría individualizar el tocado, sin duda la joya más ostensible. Esta tipología de diadema se suma a la única conocida hasta el momento para este horizonte: la cinta rectangular lisa sujeta en la parte posterior mediante ligamentos que se aseguraban con orificios abiertos en los extremos distales de la cinta.

También la laminita rectangular recuperada entre los restos del expolio de otro hipogeo presenta una tipología y una elaboración, incluida su decoración repujada, conocida en otras joyas de este horizonte. Se trata de una pequeña pieza muy alargada que conserva un extremo original con cuatro orificios muy irregulares y de distinto tamaño - uno de ellos rectificado- para pasar una ligadura y cerrar la pieza supuestamente en torno al brazo (Figura 8f, Fig. 11). Es el único fragmento decorado mediante una línea de puntos repujados que bordea los lados largos. Es probable que corresponda a un pequeño fragmento de una joya acintada de apenas $1,5 \mathrm{~cm}$ frente a los aproximadamente $3 \mathrm{~cm}$ de anchura de piezas como la diadema del ajuar campaniforme de Fuente Olmedo (Martín Valls y Delibes 1989: 24) o los casi $5 \mathrm{~cm}$ de los ejemplares portugueses de Quinta da Agua Branca y de Papagôvas (Jorge (comp.) 1995: 23 y 24). Esta escasa anchura invita a pensar que no formara parte de un tocado, sino más bien de un objeto de menor longitud, brazalete o una ajorca. Su decoración sigue un esquema desarrollado en otras piezas de este horizonte como la laminita del vertedero de Salmedina (Berzosa y Flores 2005: 483) o los pendientes de Emergeira (Torres Veras) (Jorge (comp.) 1995: 78). A diferencia del tocado que es una joya compuesta, posiblemente este fragmento perteneció a un adorno simple.

El personaje dotado de diadema áurea completaba su atuendo con un ipectoral o collar? de cuentas bicónicas y botones de casquete esférico realizados en marfil (según C. Liesau y T. Schuhmacher), impregnado con cinabrio. A todo ello se suma una espléndida cazuela de estilo campaniforme Ciempozuelos con una decoración simbólica de ciervos esquemáticos, dispuestos en un friso corrido situado en la cara externa. El conjunto presenta asociaciones, seguramente frecuentes, aunque pocas veces se ha registrado la existencia de marfiles, confundidos con hueso, y de cinabrio, interpretado como ocre, y en intervenciones poco cuidadas ni siquiera se han recuperado estos elementos. La reiterada asociación de ornatos de oro, marfil y cinabrio podría indicar circuitos muy bien prefijados y coordinados. Resulta evidente que el oro se asocia a personajes de alto rango con capacidad de amortizar materias primas exóticas de procedencia lejana o muy lejana cuya adquisición no está al alcance de la mayoría y que de manera aislada (Bueno et al., 2005, 2007; Benítez de Lago et al., 2009), y sobre todo, en asociación, son la expresión de poder

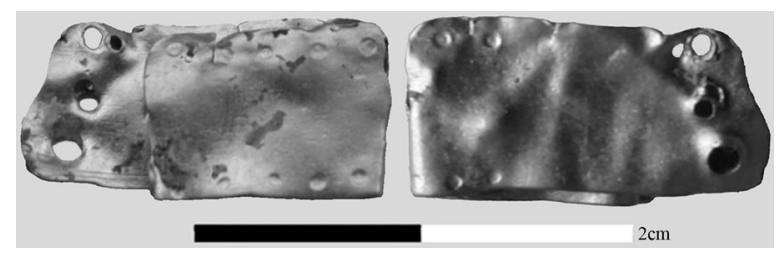

Fig. 11. Laminita de oro con decoración repujada de Camino de las Yeseras (San Fernando de Henares, Madrid). 
de una élite ostentada por jóvenes varones a quienes se les reconoce su liderazgo más allá de la muerte mediante amortizaciones costosas por su materia prima, su elaboración especializada y el complejo mecanismo de su adquisición.

\section{CONCLUSIONES FINALES}

El hecho singular de las tumbas de Camino de las Yeseras es, como apuntamos la ausencia de armas, en las que se ha querido ver el símbolo de la coerción. En su lugar contamos en la tumba intacta con una cazuela decorada con ciervos esquemáticos cuyo simbolismo quizás indicativo de un liderazgo también de carácter "religioso" cuyos ornamentos y, muy especialmente los tocados áureos destacados en su cabeza formaban parte de una "liturgia" complementaria a la representación gráfica reproducida en el contenedor cerámico que le acompañaba.

Pero además del valor y simbolismo del oro reconocido en este contexto intacto, hay que referirse a los dos hallazgos áureos recuperados en sendas tumbas expoliadas cuyos ajuares contenían cerámica campaniforme de tipo Ciempozuelos. No parece casual que las dos únicas tumbas profanadas que se han documentado en este yacimiento contuvieran joyas de oro, de las que los saqueadores "extraviaron" una cuenta tubular similar a las del tocado antes citado y el fragmento de cinta con decoración repujada (Fig. 8e y f; Fig. 11). Este último se encontró fuera de la cámara del hipogeo, entre las piedras que rellenaban el acceso en chimenea las cuales fueron recolocadas tras la violación y remoción de la tumba. En cambio la cuenta cilíndrica se localizó en el interior de la fosa funeraria junto a los fragmentos óseos de los cuerpos inhumados y los restos del ajuar cerámico removidos que quedaron tras la retirada de buena parte del contenido de las tumbas.

Seguramente no se buscaba sólo el oro o alguna de las otras materias exóticas que pudieran contener por la codicia de obtener un beneficio material, sino por la apropiación de lo excepcional, ya fuera por su valor intrínseco o, más probablemente, por su significado, tratando de emular, mediante la posesión de las enseñas simbólicas, el estatus que representan. Quizás sea expresivo de esta intención el hecho de que no se trata de una rapiña exhaustiva, sino que intencionadamente las cerámicas se rompen para sustraer sólo una parte de cada uno de los recipientes. De igual manera, se exhuman los restos óseos del difunto, pero se dejan pequeñas porciones, mientras que se retiren aquellas piezas que, por su procedencia, pueden ser la evidencia de unas relaciones sociales singulares.

A los tres conjuntos funerarios hay que sumar otra lámina perteneciente a un fragmento de ornato (Fig. 8d y Fig. 12) localizada en la zona central del yacimiento, dentro del recinto del foso más interno. Tampoco descartamos que esta pieza pudiera proceder de alguna de las tumbas expoliadas, quizás no excavada en las intervenciones practicadas en el yacimiento y que fuera trasladada a una zona de actividad. De confirmarse esta hipótesis estamos ante un hallazgo con significado similar al de las dos tumbas saqueadas, de manera que el hecho de la profanación de tumbas singulares tendría en este yacimiento un nuevo referente más convirtiéndose en un fenómeno relativamente frecuente.

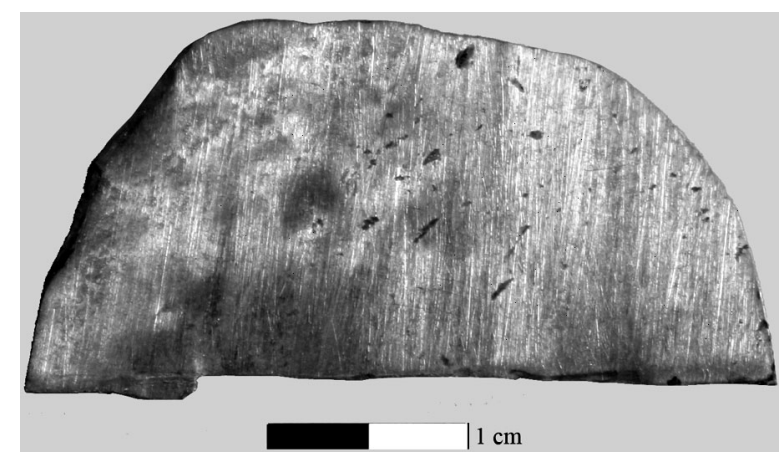

Fig. 12. Fragmento de lámina de oro de Camino de las Yeseras (San Fernando de Henares, Madrid).

El expolio de tumbas singulares de Camino de las Yeseras no es un fenómeno nuevo ni exclusivo de su necrópolis. Está documentado en contextos funerarios campaniformes de otras zonas peninsulares como Almenara de Adaja (Valladolid) donde se han reconocido tumbas saqueadas, alguna de ellas igualmente excepcionales por contener, como la tumba madrileña, un recipiente cerámico con decoración simbólica de ciervos y soles (Guerra y Delibes 2004). Esta reiteración tiene seguramente un significado que podría ir 
más allá de acciones individuales, pero queda claro que no resultó difícil la localización de estas tumbas singulares ya que una de sus características es la monumentalización de su señalización en consonancia con la relevancia del individuo enterrado. Se destacan en el paisaje por las dimensiones de los túmulos que las cubrían, el mayor tamaño de las piedras que los formaron, las características arquitectónicas específicas de las tumbas y de su ajuar.

Todavía nos encontramos lejos de desvelar el significado real de estas profanaciones, pero resulta especialmente llamativo que los sujetos que llevaron a cabo los expolios se mostraran respetuosos y, una vez finalizada su acción, volvieran a colocar toda la cobertura de la tumba, pese a la inversión de trabajo que ello conllevaba. ¿Se trataba de mantener en secreto su acción? Es posible, pero creemos más probable que nos encontremos ante un acto ritual, sancionado por toda o parte de la comunidad la cual participaba en él de manera directa o indirecta.

A favor de la relación con un acto ritual, está la premeditada selección en la apropiación que respetaba una parte de los restos esqueléticos, en general pequeñas porciones, y la intencionada rotura de los contenedores cerámicos con el fin de mantener parte en el depósito funerario retirando aproximadamente la mitad de cada vaso (Guerra y Delibes 2004). Frente a ello el oro y otros objetos de marcado significado simbólico eran sustraídos. Una vez terminada la acción los participantes o sus colaboradores procedían a la reconstrucción del paisaje funerario manteniendo la visualización jerárquica de las tumbas, pese a la inversión de trabajo que ello suponía. Incluso en uno de los conjuntos de Camino de las Yeseras tras el vaciado del contexto funerario se depositaron dos perros a los que se les propinó un fuerte golpe en la cabeza. Sobre sus restos se echaron las tierras y los restos del expolio y se coronó la acción con la reconstrucción de la cobertura tumular.

A los antiguos datos que poseíamos acerca del inicio de la metalurgia en la región de Madrid se suman ahora los que aporta el yacimiento de $\mathrm{Ca}$ mino de las Yeseras que refuerza las evidencias sobre el valor simbólico y de prestigio que tiene el metal, en especial el oro, justificando el destino final de una buena parte de la producción de esta industria en ajuares funerarios, como elementos de distinción de una élite. Ese significado adquie- re todavía mayor fuerza por su asociación con otras materias primas y elementos exóticos que posiblemente llegaran a esta área del centro peninsular junto a los ornatos de oro dentro de redes de distribución muy bien definidas a juzgar por las reiteraciones de algunas de estas asociaciones. El significado simbólico del oro y las armas de cobre así como del resto de los elementos de prestigio pudo mantenerse más allá de su amortización en los ajuares funerarios y ser en parte la causa de las manipulaciones reiteradas que sufren los conjuntos tumbales más relevantes.

\section{BIBLIOGRAFÍA}

Baena, J. y Blasco, C. 1999: “Análisis macroespacial apoyado en los SIG. El Horizonte campaniforme en la Región de Madrid". En J. Baena, C. Blasco y F. Quesada (eds.): Los SIG y el análisis espacial en Arqueología. Colección Estudios 51, UAM. Madrid.

Benítez de Lugo, L.; Bueno, P.; Barroso, R.; Balbín, R. y López Sáez, J.A. (ed.) 2009: El Valle de Huecas (Huecas, Toledo), Arqueología, medio ambiente y obras públicas. Anthropos.

Berzosa, R. y Flores, R. 2005: "El conjunto funerario campaniforme del Vertedero de La Salmedina (Distrito de Villa de Vallecas, Madrid". En Rojo et al. (coords.): El Campaniforme en la Península Ibérica y su contexto europeo, Universidad de Valladolid: 481-494.

Blasco, C. y Rovira, S. 1992-93: “La metalurgia del cobre y del bronce en la región de Madrid". Tabona VIII (II): 397-415.

Blasco, C.; Delibes, G.; Baena, J.; Liesau, C. y Ríos, P. 2007: "El poblado calcolítico de Camino de las Yeseras (San Fernando de Henares, Madrid). Un escenario favorable para el estudio de la incidencia campaniforme en el interior peninsular". Trabajos de Prehistoria 64 (1): 151-163.

Blasco, C.; Liesau, C.; Delibes, G.; Baquedano, E. y Rodríguez Cifuentes, M. 2005: "Enterramientos campaniformes en ambiente doméstico: el yacimiento de Camino de las Yeseras (San Fernando de Henares, Madrid)". En M. Rojo et al. (coords.): El Campaniforme en la Península Ibérica y su contexto europeo, Universidad de Valladolid: 457-479.

Bueno, P.; Barroso, R. y Balbín, R. 2005: "Ritual campaniforme, ritual colectivo: la necrópolis de cuevas artificiales del Valle de las Higueras (Huecas, Toledo)". Trabajos de Prehistoria 62 (2): 67-90.

Bueno, P.; Barroso, R. y Balbín, R. 2007: “Agricultores y metalúrgicos". En J. Pereira Sieso (coord.): Prehistoria y Protohistoria de la Meseta Sur (Castilla-La Mancha). Ciudad Real: 57-94. 
Delibes, G. y Montero I. (coords.) 1999: Las primeras etapas metalúrgicas en la Península Ibérica. II. Estudios regionales. Instituto Universitario Ortega y Gasset. Madrid.

Guerra, E. y Delibes, G. 2004: “Contexto y posible significado de un cuenco Ciempozuelos con decoración simbólica de ciervos hallado en Almenara de Adaja (Valladolid)". En E. Baquedano y S. Rubio Jara (eds.): Miscelánea en Homenaje a Emiliano Aguirre. Arqueología. Zona Arqueológica 4 (4): 116-125.

Harrison, R. 1977: The Bell Beaker Cultures of Spain and Portugal. Cambridge-Massachusetts.

Harrison, R.; Quero, S. y Priego, M. ${ }^{\mathrm{a} C}$. 1975: "Beaker metallurgy in Spain”. Antiquity XLIV: 273-278.

Hartmann, A. 1982: Prähistorische Golfunde us Europa II. Spektralanalytische Untersuchungen und deren Auswertun, S.A.M. 5 Gbr. Mann. Berlín.

Hernando, A. 1983: "La orfebrería durante el Calcolítico y el Bronce Antiguo en la Península Ibérica". Trabajos de Prehistoria 40: 83-138.

Hernando, A. 1989: "Inicios de la orfebrería en la Península Ibérica". En El oro en la España prerromana. Zugarto Ediciones. Madrid: 32-45.

Hurtado, V. y Hunt, M. 1999: “Extremadura” En G. Delibes y I. Montero (coords.): Las primeras sociedades metalúrgicas. Madrid: 241-266.

Jorge, S.O. (comp.) 1995: A Idade do Bronze em Portugal, discursos de Poder. Instituto portugués de Museos. Lisboa.

Liesau, C.; Blasco, C.; Ríos, P.; Vega, J.; Menduiña, R.; Blanco, J.F.; Baena, J.; Herrera, T.; Petri, A. y Gómez, J.L. 2008: “Un espacio compartido por vivos y muertos: El poblado calcolítico de fosos de Camino de las Yeseras (San Fernando de Henares, Madrid)". Complutum 18 (1): 97-120.

Losada, H. 1976: "El Dolmen de Entretérminos". Trabajos de Prehistoria 33: 209-221.

Martín Valls, R. y Delibes, G. 1989: La cultura del Vaso campaniforme en las campiñas meridionales del Duero: el enterramiento de Fuente-Olmedo. Monografía del Museo Arqueológico Provincial de Valladolid.

Molina, F. y Cámara, J.A. 2005: Guía del yacimiento arqueológico. Los Millares. Junta de Andalucía. Consejería de Cultura.

Montero, I. 1998: "Aprovechamiento de recursos minerales y comercialización de objetos metálicos: una perspectiva analítica". En G. Delibes (coord.): Minerales y metales en la Prehistoria reciente. Algunos testimonios de su explotación y laboreo en la Península Ibérica. Studia Arqueológica 88. Valladolid: 199-226.

Montero, I. y Rovira, S. 1991: "El oro y sus aleaciones en la orfebrería prerromana". Archivo Español de Arqueología 64: 7-21.
Nocete, F. (coord.) 2004: Odiel. Proyecto de Investigación arqueológica para el análisis del origen de la desigualdad social en el suroeste de la Península Ibérica. Arqueología Monografías 19. Junta de Andalucía. Consejería de Cultura. Sevilla.

Perea, A. 1989: "Tecnología y métodos de estudio". En El oro en la España prerromana. Zugarto Ediciones. Madrid: 24-31.

Perea, A. 1991: Orfebrería prerromana. Arqueología del oro. Comunidad de Madrid. Caja Madrid.

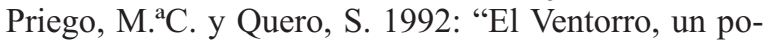
blado prehistórico de los albores de la metalurgia". Estudios de Prehistoria y Arqueología Madrileñas 8.

Rodríguez, M. 2008: La investigación de la actividad metalúrgica durante el III milenio A.N.E. en el suroeste peninsular. La arqueometalurgia y la aplicación de análisis metalográficos y composicionales en el estudio de la producción de objetos de metal. British Archaeological Report. International series 1760. Oxford.

Rodríguez de la Esperanza, M. ${ }^{\mathrm{a} J}$. 2004: "La primera industria del oro en el Valle del Ebro". Anejos al Archivo español de Arqueología XXXII: 189-195.

Rodríguez de la Esperanza, M.'J. 2005: Metalurgia y metalúrgicos en el Valle del Ebro. Bibliotheca Archaeologica Hispana 24. Real Academia de la Historia. Madrid.

Rovira, S. 1989: "Recientes aportaciones para el conocimiento de la metalurgia primitiva en la provincia de Madrid: un yacimiento campaniforme en Perales del Río (Getafe, Madrid)". XIX Congreso Nacional de Arqueología (Castellón de la Plana 1987). Zaragoza: 355-366.

Rovira LLorens, S. 1994: "Informe del estudio analítico de algunos materiales de 'El Ventorro' (Villaverde, Madrid)". Epam 9: 63-64.

Rovira, S. 2002: "Early slags and smelting by-products of copper metallurgy in Spain". En M. Bartelheim, E. Pernicka y R. Krause (eds.): Die Anfänge der Metallurgie in der Alten Welt/The Beginnings of Metallurgy in the Old World. Verlag Marie Leidorf GmbH, Rahden. Westfalia: 83-98.

Rovira, S. y Ambert, P. 2002: "Vasijas cerámicas para reducir minerales de cobre en la Península Ibérica y en la Francia Meridional". Trabajos de Prehistoria 59(1): 89-105.

Rovira, S. y Montero I. 1994: "Metalurgia campaniforme y de la Edad del Bronce en la Comunidad de Madrid". En C. Blasco (ed.): El Horizonte campaniforme en la Región de Madrid en el centenario de Ciempozuelos. Patrimonio Arqueológico del Bajo Manzanares 2. Universidad Autónoma de Madrid: 137-168.

Sánchez Palencia. F.J. y Pérez, L.C. 1989: “Los yacimientos auríferos de la Península Ibérica. Posibilidades de explotación en la Antigüedad". En El oro 